http://jurnal.stmikroyal.ac.id/index.php/jurdimas

\title{
PEMANFAATAN TEKNOLOGI KOMPUTER DALAM PENGOLAHAN NILAI SISWA BAGI GURU-GURU SMP NEGERI 2 SIMPANG EMPAT
}

\author{
Risnawati $^{* 1}$,Edi Kurniawan ${ }^{1}$, Nasrun Marpaung1 ${ }^{1}$ Masitah Handayani ${ }^{1}$, \\ Abdul Karim Syahputra ${ }^{1}$ \\ ${ }^{1}$ Program Studi Sistem Informasi, STMIK Royal Kisaran, \\ Email : $\underline{\text { rhisnawati716@gmail.com }}^{* 1}$
}

\begin{abstract}
Community Service Activities in the form of training utilization of computer technology for teachers in the processing of student value aims to provide knowledge and skills, which's expected to result in changes in knowledge, skills and attitudes of teachers and students so that process of learning and teaching can run smoothly and easily. Target audience in this Community Service activity's all teachers of SMPN 2 S.Empat which amounts to 30 people. Training activities utilization of computer technology in the world of education's presented by lecture methods, demonstrations and frequently asked questions. Lecture method's used to explain the concept of the application used is M.Excell. A demonstration method to demonstrate a process of work's the stages of each activity and practice it, while the question and answer method to give the participants the opportunity to consult in overcoming the constraints that occur in the processing of values manually. The benefits derived from this activity include improving the knowledge of teachers to be more professional in carrying out teaching and learning process either inside or outside school, can improve student learning activities through IPTEKS satisfaction, can simplify the process of calculating student value computerized with the help of M. Excell .
\end{abstract}

Keywords :Utilization of Computer Technology, Microsoft Excel, Input Value Data.

Abstrak: Kegiatan Pengabdian kepada Masyarakat berupa pelatihan pemanfaatan teknologi komputer bagi guru-guru dalam pengolahan nilai siswa ini bertujuan untuk memberikan pengetahuan dan keterampilan, yang diharapkan dapat menghasilkan perubahan pengetahuan, keterampilan dan sikap dari guru maupun siswa sehingga proses belajar dan mengajar dapat berjalan dengan lancar dan mudah.Khalayak sasaran dalam kegiatan Pengabdian kepada Masyarakat ini adalah seluruh guru SMP Negeri 2 Simpang Empat yang berjumlah 30 orang. Kegiatan pelatihan pemanfaatan teknologi komputer dalam dunia pendidikan ini disajikan dengan metode ceramah, demonstrasi dan tanya jawab. Metode ceramah digunakan untuk menjelaskan konsep tentang aplikasi yang digunakan yaitu Microsoft Excell. Metode demonstrasi untuk menunjukkan suatu proses kerja yaitu tahapan-tahapan dari setiap kegiatan dan mempraktikkannya, sementara metode tanya jawab untuk memberi kesempatan para peserta berkonsultasi dalam mengatasi kendala yang terjadi dalam pengolahan nilai secara manual.Manfaat yang diperoleh dari kegiatan ini antara lain dapatmeningkatkan pengetahuan para guru agar lebih profesional dalam melaksanakan proses belajar mengajar baik didalam atau diluar sekolah, dapat meningkatkan aktifitas pembelajaran siswa melalui penguasan IPTEKS, dapat mempermudah proses perhitungan nilai siswa secara komputerisasi dengan bantuan Microsoft Excell.

Kata Kunci : Pemanfaatan Teknologi Komputer, Microsoft Excel, Penginputan Data Nilai. 
Jurdimas (Jurnal Pengabdian Kepada Masyarakat)

Vol. I No. 1, Januari 2018, hlm. 44 - 47

Available online at

http://jurnal.stmikroyal.ac.id/index.php/jurdimas
ISSN 2614-7912 (Print)

ISSN 2622-3813 (Online)

\section{PENDAHULUAN}

Perkembangan

memberikan banyak manfaat dan kemudahan-kemudahan terutama dalam dunia pendidikan. Dengan adanya perkembangan teknologi, segala sesuatu dapat dapat dikerjakan dengan mudah, cepat, tepat dan akurat. Salah satu jenis teknologi yang berkembangan saat ini adalah komputer, dimana ada banyak aplikasi komputer yang dapat membantu dalam proses pengolahan data nilai yang salah satunya adalah Microsoft Excel.

SMP Neg. 2 Simpang Empat pada saat ini melakukan pengolahan nilai siswa secara manual. Proses manual ini tentu saja dapat menyita waktu yang banyak dalam proses pengerjaannya dan kadangkala dapat menyebabkan terjadinya human error. Hal ini disebabkan oleh terlalu banyak data yang akan diolah.

Pelatihan pemanfaatan teknologi komputer dalam pengelolaan nilai siswa bagi guru-guru di SMP Neg. 2 Simpang Empat ini dipandang sangat penting karena pelatihan tersebut dapat melatih guru-guru agar dapat mengolah nilai lebih mudah dan cepat serta membuat laporan penilaian menjadi lebih rapi.

Pengabdian kepada Masyarakat ini yang menjadi peserta adalah seluruh guru yang ada di SMP Neg. 2 Simpang Empat

Rangkaian kegiatan pengabdian masyarakat dilaksanakan selama 2 hari dan dapat diuraikan pada tabel berikut ini:
Tabel 1. Proses Kegiatan

\begin{tabular}{|c|c|c|}
\hline Waktu & Tema & Pemandu \\
\hline \multicolumn{3}{|c|}{ Jum'at, 17 Nopember 2017} \\
\hline $\begin{array}{l}08.00 \mathrm{WIB} \text { - } \\
9.00 \mathrm{WIB}\end{array}$ & Pembukaan & $\begin{array}{l}\text { Kepala Sekolah } \\
\text { SMP Neg. } 2 \\
\text { Simpang Empat }\end{array}$ \\
\hline $\begin{array}{l}09.00 \mathrm{WIB} \text { - } \\
10.00 \mathrm{WIB}\end{array}$ & $\begin{array}{l}\text { Pengenalan } \\
\text { Ms. Excell }\end{array}$ & $\begin{array}{l}\text { Risnawati, } \\
\text { S.Kom., M.Kom }\end{array}$ \\
\hline $\begin{array}{l}10.00 \mathrm{WIB} \text { - } \\
11.00 \mathrm{WIB}\end{array}$ & $\begin{array}{l}\text { Dasar- } \\
\text { Dasar } \\
\text { Rumus Ms. } \\
\text { Excell }\end{array}$ & Tim PkM \\
\hline $\begin{array}{l}11.00 \mathrm{WIB} \text { - } \\
12.00 \mathrm{WIB}\end{array}$ & $\begin{array}{l}\text { Tanya } \\
\text { jawab }\end{array}$ & Tim PkM \\
\hline \multicolumn{3}{|c|}{ Sabtu, 18 Nopember 2017} \\
\hline $\begin{array}{l}08.00 \mathrm{WIB} \text { - } \\
9.30 \mathrm{WIB}\end{array}$ & $\begin{array}{l}\text { Praktek } \\
\text { Membuat } \\
\text { Form Nilai } \\
\text { Siswa } \\
\end{array}$ & Tim PkM \\
\hline $\begin{array}{l}09.30 \mathrm{WIB} \text { - } \\
11.30 \mathrm{WIB}\end{array}$ & $\begin{array}{l}\text { Praktek } \\
\text { Memproses } \\
\text { Nilai Siswa }\end{array}$ & Tim PkM \\
\hline $\begin{array}{l}11.30 \mathrm{WIB} \text { - } \\
12.00 \mathrm{WIB}\end{array}$ & $\begin{array}{l}\text { Tanya } \\
\text { jawab }\end{array}$ & Tim PkM \\
\hline
\end{tabular}

\section{METODE}

Metode pelaksanaan dalam pengabdian masyarakat ini adalah bentuk pelatihan di dalam kelas dengan metode ceramah, diskusi dan tanya jawab serta praktek pembukuan secara langsung. Jadwal pelaksanaan pelatihan pengelolaan pembukuan dapat dilihat pada tabel berikut:

\section{Tabel 4 Jadwal Kegiatan Pengabdian} Masyarakat

\begin{tabular}{lll}
\hline Waktu & Tema & Pemandu \\
\cline { 1 - 1 } Jum'at, & 17 Nopember & 2017 \\
\hline 08.00 & & Kepala \\
WIB - & Pembukaan & Sekolah \\
9.00 & SMP Neg. \\
WIB & $\underline{2}$ \\
\hline
\end{tabular}


Jurdimas (Jurnal Pengabdian Kepada Masyarakat)

Vol. I No. 1, Januari 2018, hlm. $44-47$

Available online at

http://jurnal.stmikroyal.ac.id/index.php/jurdimas
ISSN 2614-7912 (Print)

ISSN 2622-3813 (Online)

\begin{tabular}{|c|c|c|}
\hline & \multirow[b]{2}{*}{$\begin{array}{l}\text { Pengenalan } \\
\text { Ms. Excell }\end{array}$} & $\begin{array}{l}\text { Simpang } \\
\text { Empat }\end{array}$ \\
\hline $\begin{array}{l}09.00 \\
\text { WIB - } \\
10.00 \\
\text { WIB }\end{array}$ & & $\begin{array}{l}\text { Risnawati, } \\
\text { S.Kom., } \\
\text { M.Kom }\end{array}$ \\
\hline 10.00 & Dasar- & \\
\hline $\begin{array}{l}\text { WIB - } \\
11.00 \\
\text { WIB }\end{array}$ & $\begin{array}{l}\text { Dasar } \\
\text { Rumus Ms. } \\
\text { Excell }\end{array}$ & Tim PkM \\
\hline $\begin{array}{l}11.00 \\
\text { WIB - } \\
12.00 \\
\text { WIB }\end{array}$ & $\begin{array}{l}\text { Tanya } \\
\text { jawab }\end{array}$ & Tim PkM \\
\hline Sabtu, & 8 Nopember & 2017 \\
\hline $\begin{array}{l}08.00 \\
\text { WIB - } \\
9.30 \\
\text { WIB }\end{array}$ & $\begin{array}{l}\text { Praktek } \\
\text { Membuat } \\
\text { Form Nilai } \\
\text { Siswa }\end{array}$ & Tim PkM \\
\hline $\begin{array}{l}09.30 \\
\text { WIB - } \\
11.30 \\
\text { WIB } \\
\end{array}$ & $\begin{array}{l}\text { Praktek } \\
\text { Memproses } \\
\text { Nilai Siswa }\end{array}$ & Tim PkM \\
\hline $\begin{array}{l}11.30 \\
\text { WIB - } \\
12.00 \\
\text { WIB }\end{array}$ & $\begin{array}{l}\text { Tanya } \\
\text { jawab }\end{array}$ & Tim PkM \\
\hline
\end{tabular}

\section{PEMBAHASAN}

Pelaksanaan kegiatan pengabdian ini berjalan sesuai dengan rencana yang telah ditetapkan. Hal ini disebabkan oleh adanya kerjasama yang baik antara tim pelaksana pengabdian dengan para guru yang terlibat. Dari ke-30 orang peserta yang direncanakan, semua peserta hadir untuk mengikuti pelatihan sejak dimulainya pembukaan acara sampai dengan penutupan. Pada saat pelaksanaan, semua peserta mengikuti kegiatan pelatihan tersebut dengan semangat dan antusiasme yang tinggi. Hal ini terbukti dengan adanya perhatian dan ketekunan para peserta dalam menjalankan semua instruksi yang diberikan oleh tim pelaksana. Pada waktu pelatihan berlangsung, peserta juga terlihat aktif dalam menanyakan segala hal yang belum mereka ketahui.

Para narasumber mendampingi peserta dengan penuh tanggungjawab dan kesabaran untuk memastikan bahwa seluruh peserta pelatihan dapat menguasai materi dengan baik. Narasumber juga memanfaatkan peserta yang sudah memiliki pengetahuan lebih banyak dari peserta lainnya untuk dapat memberikan bimbingan. Hal tersebut dapat membuat suasana pelatihan menjadi lebih akrab diantara narasumber dan guru-guru. Oleh sebab itu, suasana ini memberikan capaian yang lebih positif demi tercapainya tujuan pelatihan.

Adapun hasil yang dicapai dalam pelatihan ini adalah peserta pelatihan yang merupakan guru-guru dapat mengolah nilai siswa lebih efektif dan efisien karena tidak perlu lagi menghitung nilai satu persatu. Selain itu, pelatihan ini memberikan manfaat kepada guru-guru bagaimana memanfaatkan teknologi khususnya komputer dengan lebih bijak lagi.

Materi dalam pelatihan ini dibuat sesuai dengan kebutuhan guru-guru dalam mengolah nilai dengan cepat. Bagi guru-guru yang yang sudah memiliki keterampilan dalam menggunakan komputer dan menggunakan Ms. Excell dalam proses perhitungan maka mereka akan lebih mudah menguasai rumusrumus yang diajarkan oleh narasumber. Tetapi sebaliknya, bagi guru-guru yang masih belum terbiasa menggunakan rumus-rumus perhitungan yang diberikan, 
Jurdimas (Jurnal Pengabdian Kepada Masyarakat)

Vol. I No. 1, Januari 2018, hlm. 44 - 47

Available online at

http://jurnal.stmikroyal.ac.id/index.php/jurdimas
ISSN 2614-7912 (Print)

ISSN 2622-3813 (Online) maka mereka lebih lambat dalam proses pengerjaan yang nilai tersebut karena sebelum memasukkan rumus yang diinginkan maka mereka terlebih dahulu harus mengetikkan angka-angka dari nilai tersebut. Bagi yang belum terbiasa, otomatis hal ini dapat memperlama proses pengolahan nilai.

Akan tetapi, berdasarkan pemantauan yang dilakukan oleh tim pelaksana selama proses pelatihan, kemajuan yang dicapai oleh sebagian besar guru-guru yang mengikuti pelatihan memiliki kemajuan yang baik, diantaranya dari yang menggunakan komputer untuk menonton video saja, sekarang para guru dapat menggunakan aplikasi komputer dalam proses pengolahan nilai siswa mereka dengan lebih mudah dan cepat.

Adapun contoh perhitungan nilai siswa dalam pelatihan dapat dilihat pada gambar di bawah ini:

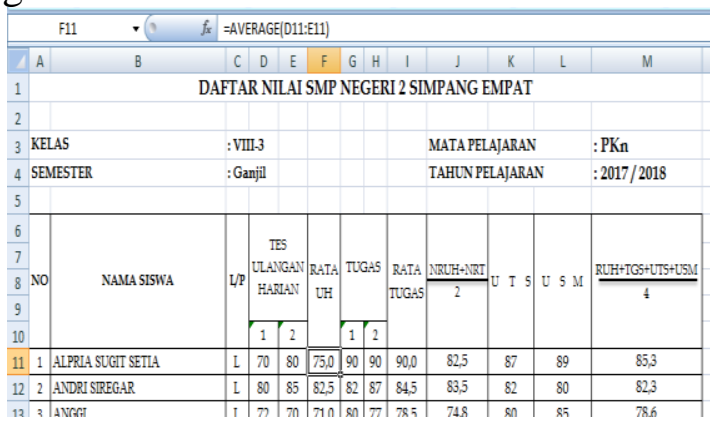

Gambar 8 Tampilan Perhitungan Nilai Menggunakan Rumus

Gambar di atas menunjukkan adanya fungsi AVERAGE untuk menghitung nilai rata-rata dari beberapa nilai seperti nilai ulangan harian, nilai tugas, nilai UTS dan nilai USM. Dimana rata-rata terakhir dari nilai tersebut merupakan nilai yang akan diinputkan ke dalam raport siswa.

\section{SIMPULAN}

Berdasarkan kegiatan pengabdian yang telah dilakukan maka dapat disimpulkan bahwa:

1. Kegiatan Pengabdian Masyarakat ini mengambil judul Pemanfaatan Teknologi Komputer dalam Pengolahan Nilai Siswa Bagi GuruGuru SMP Negeri 2 Simpang Empat dilaksanakan selama 2 hari yaitu pada tanggal 17 Nopember - 18 Nopember 2017.

2. Peserta Kegiatan adalah seluruh guru yang ada di SMP Negeri 2 Simpang Empat.

3. Pelatihan ini sangat bermanfaat bagi guru-guru karena setelah dilaksanakan pelatihan selanjutnya mereka dapat menerapkan proses perhitungan nilai secara komputerisasi sehingg waktu yang digunakan dalam proses perhitungan nilai menjadilebih cepat dan tepat.

4. Hasil dari kegiatan PkM ini adalah pelatihan berjalan dengan baik, lancar dan mendapat respon yang sangat positif dari peserta, hal ini terlihat dari banyaknya pertanyaan-pertanyaan yang diajukan peserta kepada narasumber.

\section{DAFTAR PUSTAKA}

Christoper Lee.2010. Buku Pintar Ms. Excel untuk Pemula.Jakarta. Mediakita

Ir. Pandapotan Sianipar.2008.Cara Mudah Menggunakan Microsoft Excel 2010.Jakarta;Elex Media Komputindo 